\title{
Are teachers knowledgeable and confident about dealing with allergy emergencies?
}

\author{
W Watson ${ }^{1,2^{*}}$, AM Woodrow ${ }^{2}$, A Bruce $^{3}$, A Power $^{3}$ \\ From Canadian Society of Allergy and Clinical Immunology Annual Scientific Meeting 2009 \\ Halifax, Canada. 22-25 October 2009
}

\section{Introduction}

There is little information on teachers' perspectives on assessment and management of allergy emergencies at school.

\section{Method}

An electronic survey was sent to school boards for distribution to all schools.

\section{Results}

724 teachers (8\%) completed the survey. $48 \%$ had at least one student under their direct supervision with a severe allergy. $28 \%$ believed that all students with severe allergies had a management plan for treatment. 18\% never reviewed this plan. More than $80 \%$ were confident in recognizing and knowing what to do for a severe reaction, and in using an epinephrine auto-injector. Teachers learned auto-injector technique from public/community health professionals (63\%), parents (19\%), or were self-taught (7\%). 12\% had no instruction. Children carried the auto-injector in $50 \%$ of cases. $11 \%$ reported that auto-injectors were locked in the principal's office and $21 \%$ were uncertain of its location. $91 \%$ identified common causes of anaphylaxis. More than $70 \%$ would administer the auto-injector with symptoms such as difficulty swallowing, looking blue, loss of consciousness, tongue swelling or shortness of breath after possible ingestion; less than 53\% would administer the autoinjector for generalized itching, generalized hives, or feeling faint. $24 \%$ would administer the auto-injector without symptoms. 59\% identified the appropriate level of activity after auto-injector use. To reduce risk of an allergic reaction, $80 \%$ thought that instructing the child not to share food, $69 \%$ thought that washing hands with soap and water after eating, and $66 \%$ thought that a

'Department of Pediatrics, Dalhousie University; Canada total ban of peanut-containing food would be effective. $25 \%$ incorrectly thought that using a hand sanitizer would reduce risk.

\section{Hypothesis}

Development of standardized training/protocols for all schools may increase teachers' knowledge and confidence in managing allergy emergencies.

\section{Author details}

${ }^{1}$ Department of Pediatrics, Dalhousie University; Canada. ${ }^{2}$ IWK Health Centre, Canada . ${ }^{3}$ Nova Scotia Department of Education, Halifax, Nova Scotia, Canada.

Published: 12 May 2010

doi:10.1186/1710-1492-6-S1-P10

Cite this article as: Watson et al:: Are teachers knowledgeable and confident about dealing with allergy emergencies?. Allergy, Asthma \& Clinical Immunology 2010 6(Suppl 1):P10.
Submit your next manuscript to BioMed Central and take full advantage of:

- Convenient online submission

- Thorough peer review

- No space constraints or color figure charges

- Immediate publication on acceptance

- Inclusion in PubMed, CAS, Scopus and Google Scholar

- Research which is freely available for redistribution

Submit your manuscript at www.biomedcentral.com/submit
C Biomed Central 